\title{
Origin of the Bubble Defect in the Extrusion Coating Process
}

\author{
C. Sollogoub, ${ }^{1}$ P. Montmitonnet, ${ }^{1}$ Y. Demay, ${ }^{1}$ J.F. Agassant, ${ }^{1}$ P. Deparis ${ }^{2}$ \\ ${ }^{1}$ Mines-Paristech, Centre de Mise en Forme des Matériaux, UMR CNRS/Mines-Paristech 7635, \\ BP 207-06904 Sophia Antipolis Cedex - France
}

${ }^{2}$ ARCELOR-MITTAL Research, Voie Romaine, 57280 Maizieres les Metz, France

\begin{abstract}
During the extrusion coating process, a polymer film is extruded through a flat die, stretched in air, then coated on a substrate (steel sheet in our case) in a laminator consisting of a chill roll and a flexible pressure roll. The nip, i.e., the area formed by the contact between the pressure and the chill rolls, constitutes the very heart of the extrusion coating process. Indeed, in this region, some of the most critical properties, such as adhesion, barrier properties, optical properties, are achieved. The thermomechanical analysis of Sollogoub et al., Polym. Eng. Sci., 48, 1634 (2008), was used to study the origin of the bubble defect appearing during the extrusion coating process. First, we investigate the influence of process parameters on the bubble defect. Then, we compute the thermomechanical parameters of the process, and finally, we derive a realistic bubble defect appearance criterion. POLYM. ENG. SCI., 00:000-000, 2010. @ 2010 Society of Plastics Engineers
\end{abstract}

\section{INTRODUCTION}

Extrusion coating is a very common process used to obtain a multilayered structure, by coating a substrate (paper, aluminum foil, steel sheet, etc.) with polymer films. This process combines two steps: a film extrusion and stretching step, very similar to the cast film process, and a coating step. In this last step, the substrate and the polymer film are pressed in a laminator, constituted by a chill roll and a press roll, which is covered with a rubber layer. As a consequence, the contact between the two rolls is a rectangular surface, whose width depends on the nip load, the gap between chill and press rolls and the hardness of the rubber layer. Then, the coated substrate is wrapped around the chill roll for additional cooling, thanks to the stripping roll (Fig. 1).

Correspondence to: Cyrille Sollogoub; e-mail: cyrille.sollogoub@cnam.fr DOI 10.1002/pen.21802

View this article online at wileyonlinelibrary.com.

(C) 2010 Society of Plastics Engineers
In the nip, the polymer is simultaneously pressed by the press roll against the substrate and cooled by the chill roll. To obtain a final product presenting good properties (adhesion between polymer film and substrate, barrier and optical properties), it is important to control the thermomechanical phenomena occurring within the nip. This is quite difficult because of the numerous process variables that need to be considered. That is the reason why the origin of the defects (poor adhesion, bad barrier properties, or mechanical strengths) is not always understood.

A good adhesion between the polymer film and the substrate is generally the most essential property that one tries to achieve for a coated product (see for example, Goslin and Sweeney [1], Guillote and McLaughlin [2], Hammond and Hansen [3], Kuusipalo and Savolainen [4], and Stralin and Hjertberg [5]). However, in our process, adhesion between the polymer film and the steel sheet was achieved by a postheating treatment after the nip exit thanks to infrared ovens, which leads to a very good final adhesion.

Much more disturbing were the defects that affected the homogeneity and integrity of the polymer film: pinholes and bubbles. Pinholes in the coated polymer film (Fig. 2) clearly damaged the barrier properties. The origin of this defect was due to the presence of impurities in the film or on the substrate. Bubbles, i.e., air bubbles of variable dimension, were located at the interface between the substrate and the polymer film (Fig. 3). They damaged the aesthetic aspect of the film, but more seriously they could initiate localized ruptures in the film, for example, during a subsequent deep drawing forming process. In this article, we will focus on this bubble defect.

The thermomechanical analysis of the extrusion coating process, presented in a previous article [6], has shown that there is no macroscopic polymer flow in the nip (as in other more classical coating processes) but a local flow in the roughness of the steel substrate surface (Fig. 4). This microscopic flow at the interface between the film and the substrate is strongly influenced simultaneously by 


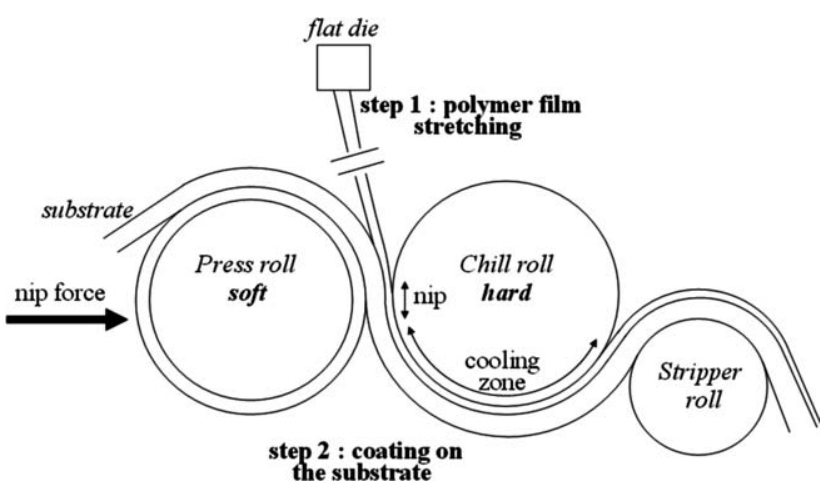

FIG. 1. Extrusion coating process.

the temperature profile in the polymer near the substrate, by the pressure induced by the nip load, and by the residence time in the nip. Several models have been then proposed, giving access to the temperature profile through polymer and substrate thickness, the pressure distribution in the nip, and the filling time of the steel roughness. This analysis and these models have been used in this work to understand the bubble defect origin and predict its appearance. After an overview of the literature on the bubble defect, we propose an explanation of the defect origin and confirm it thanks to an experimental investigation.

\section{STATE OF THE ART}

In the literature, many terms are used to describe the aspect defects in extrusion coating: craters, voids, pinholes, bubbles, and dark spots. The difference between these terms is sometimes subtle and leads to some confusion among the authors.

Van Ness [7] talks only about pinholes and studies the correlation of process variables with the pinhole density and adhesion. He concludes that harder pressure rolls and wider nip contact tend to increase both adhesion and pinholes. He also notices that excessive flame treatment leads to increase pinhole density.

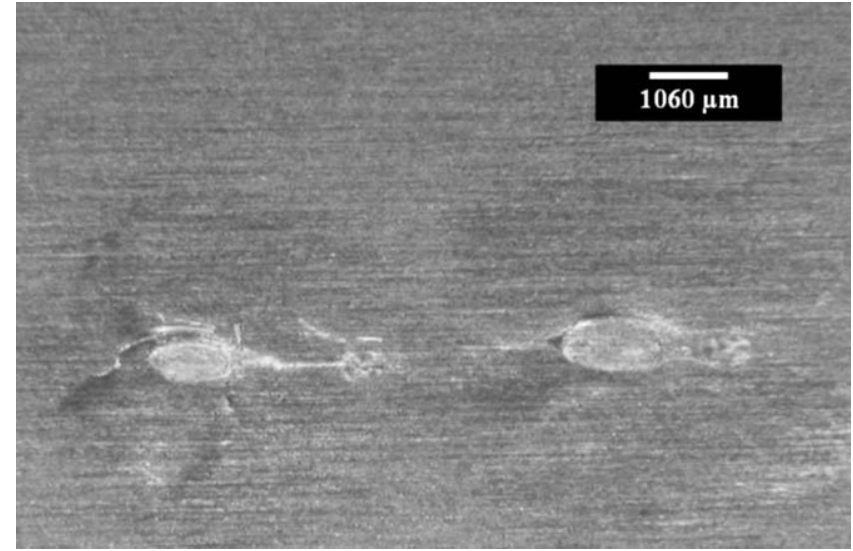

FIG. 2. Pinhole type defect.

Karszes [8,9] introduces the terms bubbles and voids. He distinguishes the bubbles, which correspond to interface problems, from the voids, considered as internal defects (that is to say in the polymer film thickness). The bubbles are due to air entrapped in rough substrates, whereas the voids origin can be entrained moisture or outgases in extrusion, too rapid cooling or improper flow. He notices that the bubbles are influenced by the same parameters as those affecting pinholes. He observes that a rough substrate surface, a low polymer thickness, and a high drawing distance produce bubbles, whereas a higher line speed reduces bubbles initiation. His conclusion is that the polymer film thickness is the leading parameter in void/bubble creation: if it is too thin, many voids and bubbles appear, and above a critical thickness, the polymer film is free of bubbles and voids.

Trouilhet and Morris [10] use a thermal model to explain the appearance of defects such as poor adhesion, curling, or poor transparency of film due to bubbles trapped in the melt. They explain, for example, bubble appearance by the fact that the coated substrate leaves the nip before polymer solidification, allowing the possibility for the entrapped air to expand.
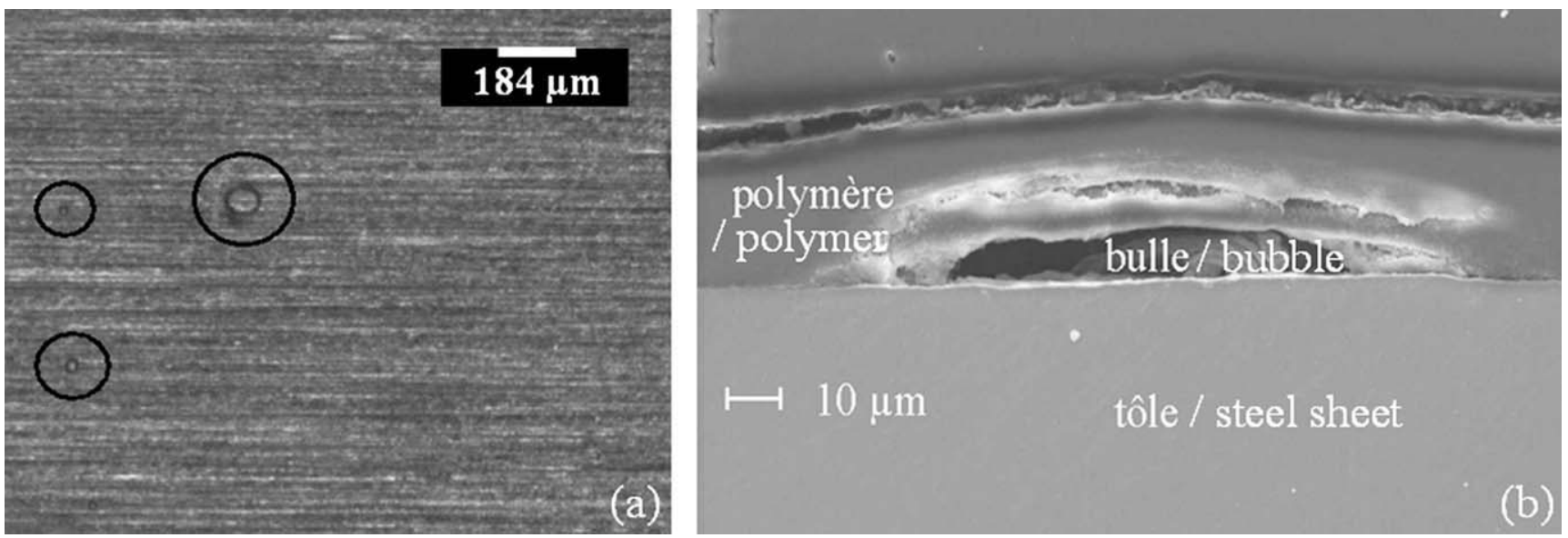

FIG. 3. Bubble type defect (a: front side, b: cross section). 


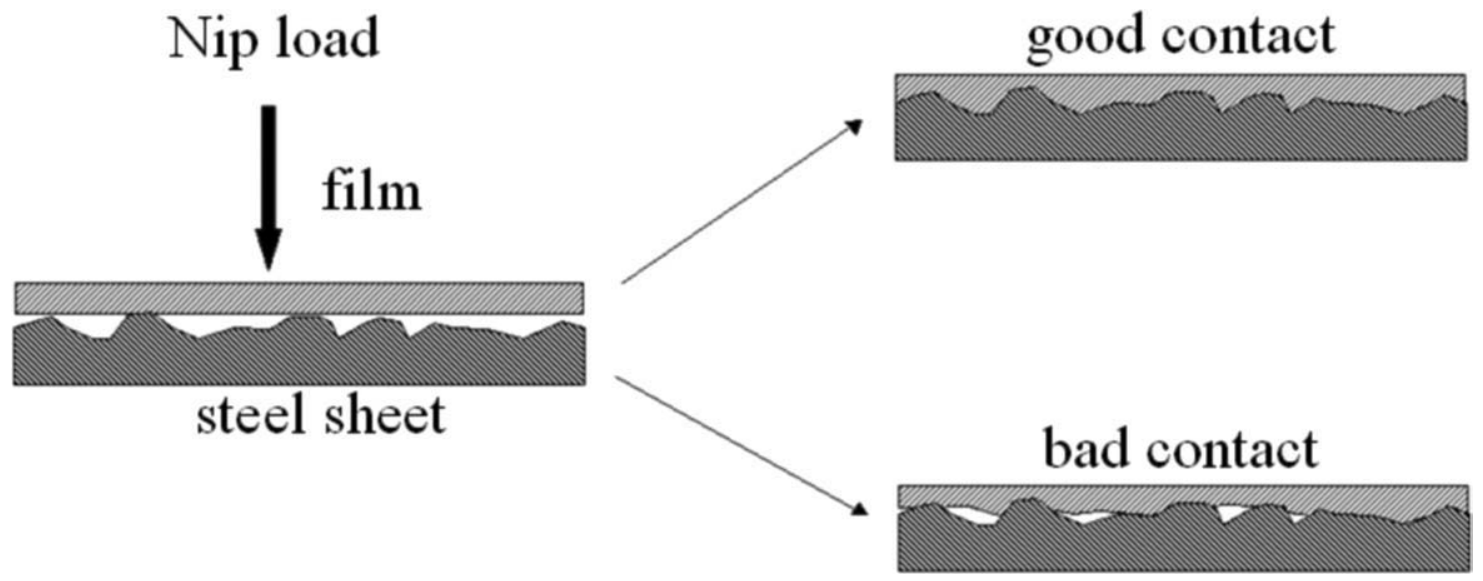

FIG. 4. The two possible consequences of the polymer flow during the passage in the nip.

This literature review highlights the link existing between the adhesion phenomena and the bubble development, as both are affected by the same parameters. This review indicates besides that numerous variables have to be considered when studying bubble defects: polymer thickness, substrate surface treatment, nip pressure, nip dimensions, line speed, and substrate roughness.

\section{EXPERIMENTAL}

\section{Speculation About Bubble Defect Origin}

In a previous article [6], we have pointed out that, although no macroscopic polymer flow at the nip entrance was observed (unlike in the calendering process for example), a microscopic polymer flow in the steel sheet roughness occurs at the interface between the steel sheet and the polymer. This microscopic flow at the interface tends to increase the contact surface between the film and the substrate.

Then, depending on the extent of this microscopic flow (which depends on the pressure profile and the res- idence time in the nip, as well as the cooling conditions in the laminator), the two following situations may occur (Fig. 4):

\begin{abstract}
"good contact": the polymer fills in all the irregularities of the substrate and the contact surface is maximal. It means that there is no air entrapped between the polymer film and the steel sheet.

"bad contact": the polymer has not reached the bottom of all the substrate surface irregularities. It means that the polymer flow has been stopped either by the polymer crystallization (or solidification) or because of a too short residence time in the nip. In this case, air is entrapped at the interface between the polymer film and the substrate, and the contact is not optimal. We can then assume that the postheating step will induce blowing of the entrapped air and coalescence of different microbubbles to develop finally macrobubbles.
\end{abstract}

\section{Experimental Investigation}

To confirm this speculation, we have studied the influence of different process parameters on bubble appearance and on their sizes and distribution.
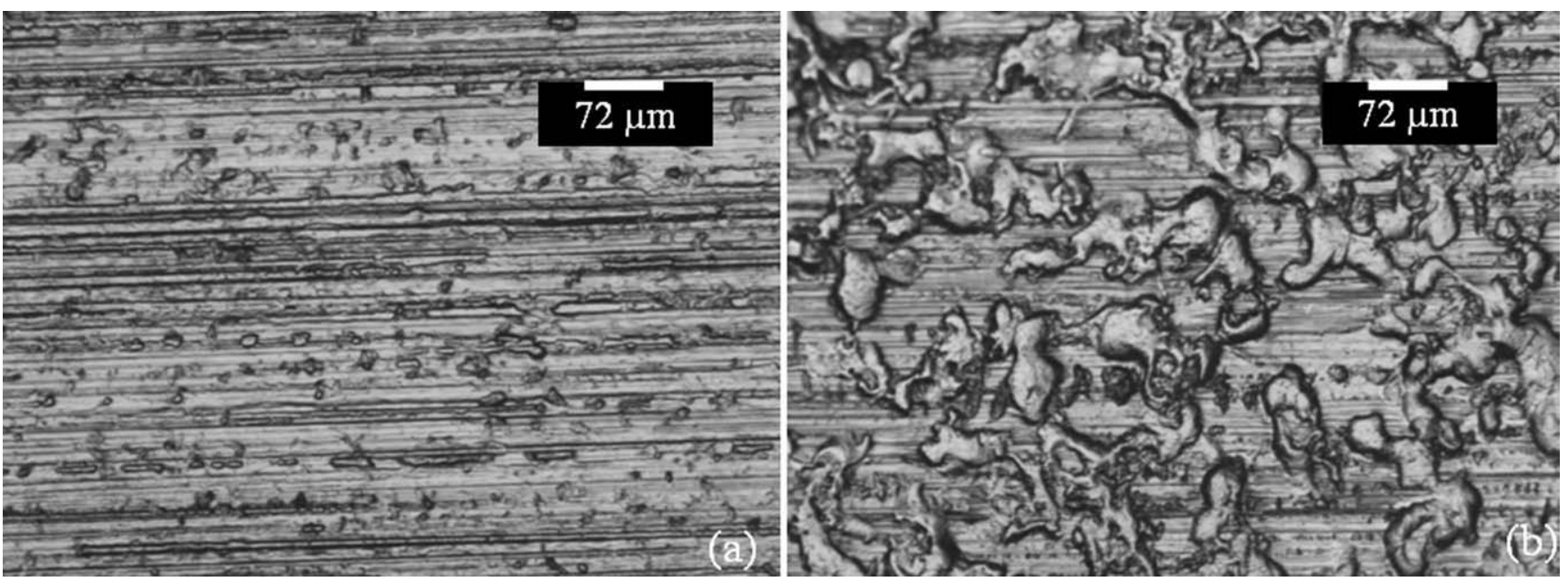

FIG. 5. Surface roughness of the two steel sheets (a: steel sheet 1, b: steel sheet 2). 
TABLE 1. Roughness parameters of the two steel sheets.

\begin{tabular}{lcc}
\hline $\begin{array}{c}\text { Roughness } \\
\text { parameters }\end{array}$ & $\begin{array}{c}\text { Roughness } \\
\text { average }(\mathrm{Sa})\end{array}$ & $\begin{array}{c}\text { Peak-Peak } \\
\text { height (St) }\end{array}$ \\
\hline Steel sheet 1 & $0.3 \mu \mathrm{m}$ & $3.5 \mu \mathrm{m}$ \\
Steel sheet 2 & $1 \mu \mathrm{m}$ & $6.5 \mu \mathrm{m}$ \\
\hline
\end{tabular}

Experiments Description. The experiments were conducted on the extrusion coating pilot line at Arcelor-Mittal Research Centre described in Sollogoub et al. [6]. The polymer used for all the experiments is PET, and it is coated on two different steel sheets, presenting two kinds of surface topology (Fig. 5): steel sheet 1 with classical rolling scratches and steel sheet 2, with an alternation of plateaus and valleys. Table 1 gives the main roughness parameters of the two steel sheets.

The typical parameters used for the reference experiment are listed in Table 2. As suggested by the literature review, we examined the effect of the following parameters: the preheated substrate temperature $\left(25,140\right.$, and $\left.200^{\circ} \mathrm{C}\right)$, the nip load $(11.5,17,23$, and $34 \mathrm{kN} / \mathrm{m})$, the line speed $(10$, 15 , and $20 \mathrm{~m} / \mathrm{min}$ ), the chill roll temperature (cooled or noncooled), the substrate roughness (two types of surface topology), and the film thickness (15 and $30 \mu \mathrm{m})$.

When examining the effect of one parameter, the others are kept constant: for example, when the line speed is increased, the film thickness is kept constant by increasing the flow rate of the extruders.

The processing conditions of the different experiments are summarized in Table 3 (the parameter which varies is in bold letters in the table).

We have noticed that the postheating stage has a decisive effect on the quality of the coated substrate. That is why, for each condition listed in Table 3, we get two samples: a sample (named A-type sample) obtained without the postheating stage (the infrared ovens are switched off) and a sample (named B-type sample) obtained with the postheating stage.

Each sample is thus designated first by a figure, corresponding to a set of conditions listed in Table 3, and then by a letter $\mathrm{A}$ or $\mathrm{B}$, giving information on the existence or not of a postheating stage.

Observation of the Samples and Characterization of the Defect. The two types of samples have been separately observed.

TABLE 2. Standard set of coating conditions.

\begin{tabular}{lc} 
Stretching distance & $21.5 \mathrm{~cm}$ \\
Nip load & $17 \mathrm{kN} / \mathrm{m}$ \\
Preheated temperature substrate & $200^{\circ} \mathrm{C}$ \\
Film thickness & $30 \mu \mathrm{m}$ \\
Line speed & $10 \mathrm{~m} / \mathrm{min}$ \\
Steel sheet & 1 \\
Chill roll temperature & $20^{\circ} \mathrm{C}$ \\
\hline
\end{tabular}

TABLE 3. Experiments performed on the pilot line to study the effect of the parameters on bubble defect.

\begin{tabular}{|c|c|c|c|c|c|c|}
\hline $\begin{array}{c}\text { Experiment } \\
\text { no. }\end{array}$ & $\begin{array}{c}\text { Preheated } \\
\text { temperature } \\
\text { substrate }\left({ }^{\circ} \mathrm{C}\right)\end{array}$ & $\begin{array}{c}\text { Nip load } \\
(\mathrm{kN} / \mathrm{m})\end{array}$ & $\begin{array}{c}\text { Line } \\
\text { speed } \\
(\mathrm{m} / \mathrm{min})\end{array}$ & $\begin{array}{l}\text { Steel } \\
\text { sheet }\end{array}$ & Chill roll & $\begin{array}{c}\text { Film } \\
\text { thickness } \\
(\mu \mathrm{m})\end{array}$ \\
\hline 1 & 200 & 17 & 10 & 1 & Cooled & 30 \\
\hline 2 & 140 & 17 & 10 & 1 & Cooled & 30 \\
\hline 3 & 25 & 17 & 10 & 1 & Cooled & 30 \\
\hline 4 & 200 & 11.5 & 10 & 1 & Cooled & 30 \\
\hline 5 & 200 & 23 & 10 & 1 & Cooled & 30 \\
\hline 6 & 200 & 34 & 10 & 1 & Cooled & 30 \\
\hline 7 & 200 & 17 & 15 & 1 & Cooled & 30 \\
\hline 8 & 200 & 17 & 20 & 1 & Cooled & 30 \\
\hline 9 & 200 & 17 & 10 & 1 & Non cooled & 30 \\
\hline 10 & 200 & 17 & 10 & 2 & Cooled & 30 \\
\hline 11 & 200 & 17 & 10 & 2 & Cooled & 15 \\
\hline
\end{tabular}

For A-type samples (without postheating stage), it seems that no bubbles at all are observed. A simple observation of the polymer film coated on the steel sheet using an optical microscope, appeared to be very instructive and convenient. Actually, as shown on Fig. 6, the observation of the coated substrate reveals an alternation of clear and dark areas. A closer observation of the clear areas allows to see the rolling scratches of the substrate surface and allows thus to conclude that, in these areas, there is a close contact (or "good contact") between the film and the substrate. On the contrary, we can assume that the dark areas correspond to zones where the contact is loose ("bad contact"), which means that the polymer has not reached the bottom of the surface irregularities. In conclusion, the microscope observation of the A-type samples offers a kind of qualitative appreciation of the contact between the film and the substrate, distinguishing areas with close contact (clear areas) and areas with loose contact (dark areas) (Fig. 6). So, when observing and comparing the A-type samples, no image analysis is used to compare the relative proportion of clear/dark areas, but a tendency of the extent of the clear and black areas is given.

On the contrary, bubbles can be observed on most of the B-type samples but with various sizes and densities. It is difficult to quantify the bubble defect, as at least three parameters must be considered: the size, the number, and the distribution of the bubbles. Moreover, it seems that this defect is not homogeneous: there can be many bubbles in some areas of the sample, whereas the bubbles can be totally absent in some others. So the quantification of the bubbles on a small area, by an image analysis method for example, would not be representative of the whole sample. As a consequence, in this study, no systematic quantification of the bubble defect was performed. So, when observing and comparing the B-type samples, we just qualitatively describe the size and density of the bubbles.

Influence of Different Processing Parameters on Bubble Defect. In this experimental section, we will observe first A-type and then B-type samples obtained with the 


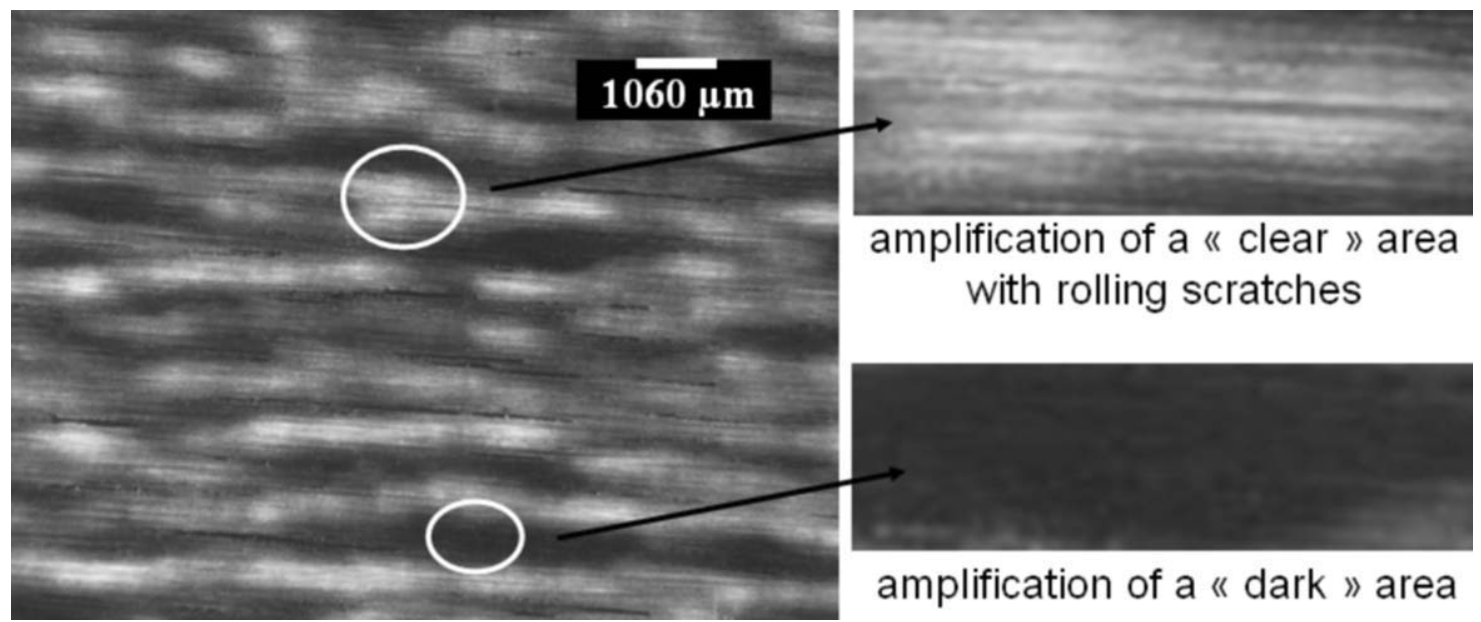

FIG. 6. Microscope observation of a coated substrate, obtained without postheating stage.

different processing parameters listed in Table 3. The influence of different processing parameters on the defect will be investigated.

Influence of the Preheating Substrate Temperature. Experiments were performed with three preheating substrate temperatures: $200^{\circ} \mathrm{C}$ (Exp. 1), $140^{\circ} \mathrm{C}$ (Exp. 2), and $25^{\circ} \mathrm{C}$ (Exp. 3).

At $200^{\circ} \mathrm{C}$ (standard conditions, Sample 1A), the presence of numerous clear areas reveals that the contact between the film and the substrate is close. As the preheating substrate temperature is decreased, the clear areas tend to decrease, revealing a poor contact between the film and the substrate. For example, Fig. 7 compares the quality of the contact with two preheating substrate temperatures: $200^{\circ} \mathrm{C}$ (presence of some clear areas) and $140^{\circ} \mathrm{C}$ (quasiabsence of clear areas). Besides, it seems that when the substrate is not preheated (substrate temperature: $25^{\circ} \mathrm{C}$ ), there is no adhesion at all between the film and the substrate.

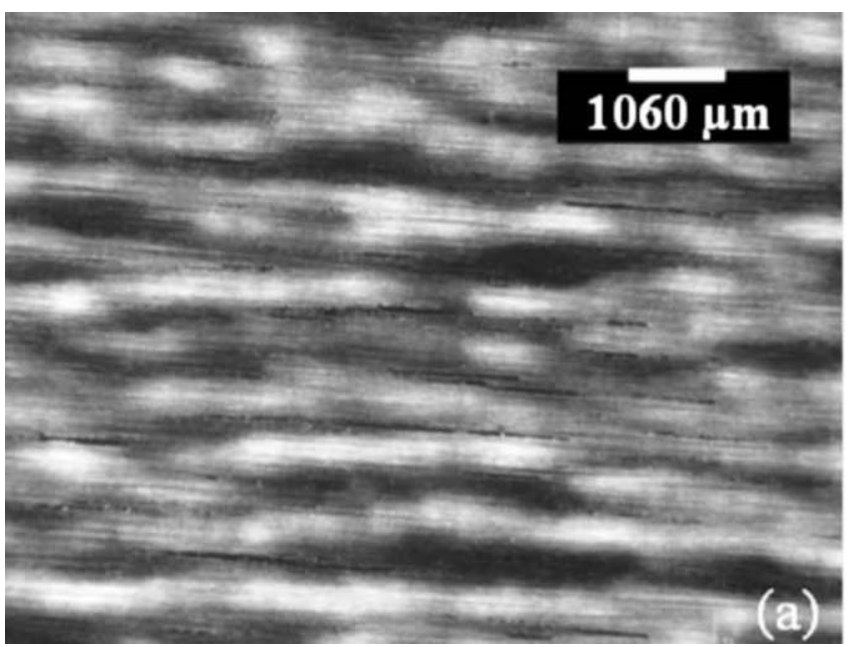

After the postheating stage, bubbles are observed on B-type samples. The number and the size of these bubbles are all the more important as the preheating substrate temperature decreases, as can be seen Fig. 8 showing the created bubbles after the postheating stage of the two samples corresponding to the two different preheating substrate temperatures $\left(200^{\circ} \mathrm{C}\right.$ and $\left.140^{\circ} \mathrm{C}\right)$. Moreover, when the substrate is not preheated, real "craters" may be observed in some areas.

Influence of the Nip Load. Increasing the nip load, from $11 \mathrm{kN} / \mathrm{m}$ (Sample $4 \mathrm{~A}$ ) to $34 \mathrm{kN} / \mathrm{m}$ (Sample 6A), seems to induce a better contact between the film and the substrate, as indicated by the more numerous and larger clear areas obtained with higher nip loads. All the corresponding samples obtained after postheating stage (Samples $4 \mathrm{~B}, 5 \mathrm{~B}$, and $6 \mathrm{~B}$ ) show some bubbles. A deeper investigation would be necessary to investigate some differences in the size, the number, and the distribution of these bubbles.

FIG. 7. Effect of the preheating substrate temperature on samples before postheating: $200^{\circ} \mathrm{C}$ (a: Sample 1A), $140^{\circ} \mathrm{C}$ (b: Sample $2 \mathrm{~A}$ ).

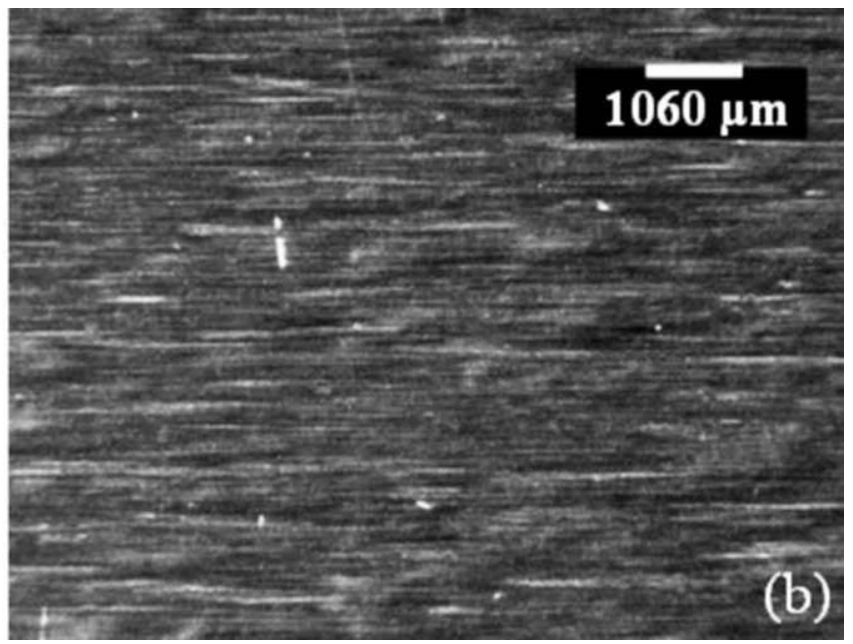



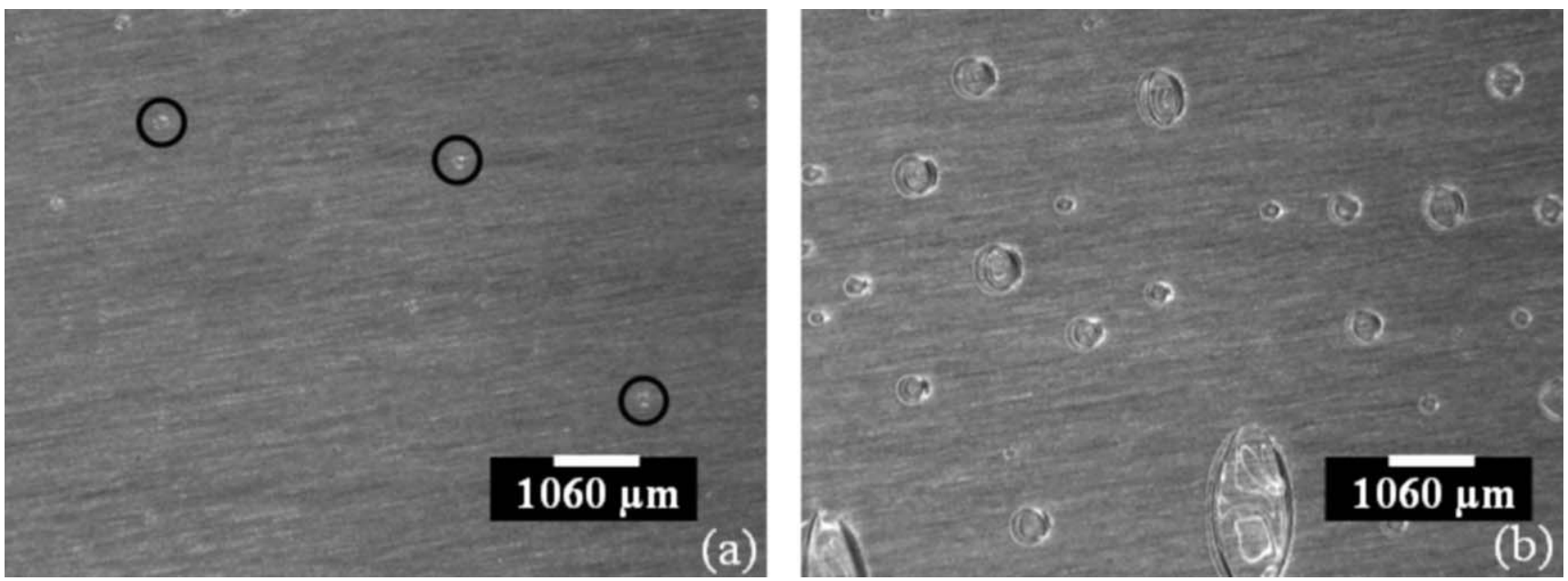

FIG. 8. Effect of the preheating substrate temperature on samples after postheating: $200^{\circ} \mathrm{C}$ (a: Sample $1 \mathrm{~B}$ ), $140^{\circ} \mathrm{C}$ (b: Sample 2B).

It is interesting to notice that, in the case of the highest nip load, a new defect appears: some scratches are visible on the polymer surface (Fig. 9). The appearance of those scratches may be correlated with a loud noise coming from the laminator. These defects are the consequence of release problems of the coated substrate, at the laminator exit. Actually, when the nip load is high, the contact and thus the adhesion are fostered not only between the film and the substrate but also between the film and the chill roll. The study of this defect is not the purpose of this article (see Foster and Edwards [11] for further investigation), but this underlines the complexity of the extrusioncoating process: all the attempts to increase the contact and the adhesion between the film and the substrate can lead as well to release problems.

Influence of the Line Speed. In Experiments 7 and 8, the line speed is increased respectively to 15 and $20 \mathrm{~m} /$ min. It appears clearly, when comparing Samples 1A

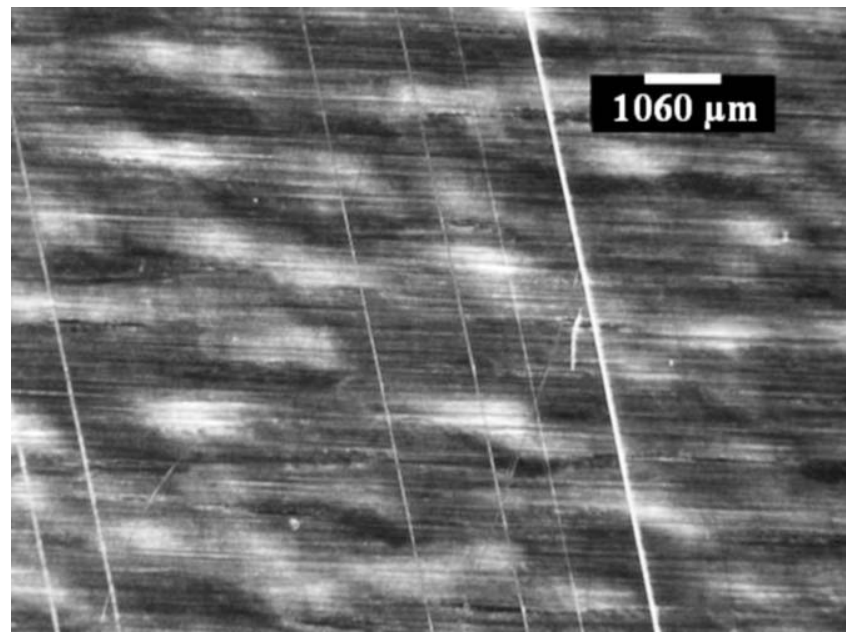

FIG. 9. Scratch defect observed for a high nip load $(34 \mathrm{kN} / \mathrm{m}$, Experiment 6).
$(10 \mathrm{~m} / \mathrm{min})$ and $7 \mathrm{~A}(15 \mathrm{~m} / \mathrm{min})$, that the contact is more intimate when increasing the line speed.

Sample 8A, obtained with the highest line speed $20 \mathrm{~m} /$ min, is more difficult to analyze (Fig. 10): when the line speed increases, leading to a much closer contact, release problems appear (scratch defect and noise) that will destroy this close contact at the nip exit. Figure 10 shows thus an alternation of areas of very close contact (clear areas) and less close contact (dark areas).

Influence of the Chill Roll Temperature. If we stop water circulation in the chill roll, we observe a significant increase of the chill roll surface temperature. When the surface temperature reaches $50^{\circ} \mathrm{C}$, bubbles disappear (Samples 9B). When the surface temperature is higher than $60^{\circ} \mathrm{C}$, the scratch defect appears, similarly to what was observed on Samples 6B.

Influence of the Steel Sheet Roughness. Until now, all the experiments were performed with the steel sheet 1 ,

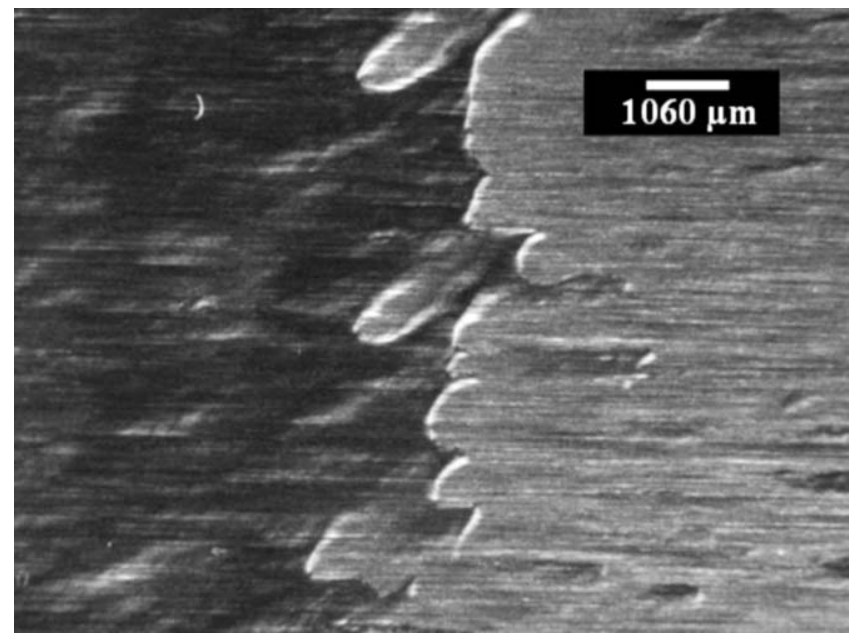

FIG. 10. Sample obtained with a high line speed $(20 \mathrm{~m} / \mathrm{min}$, Experiment 8). 

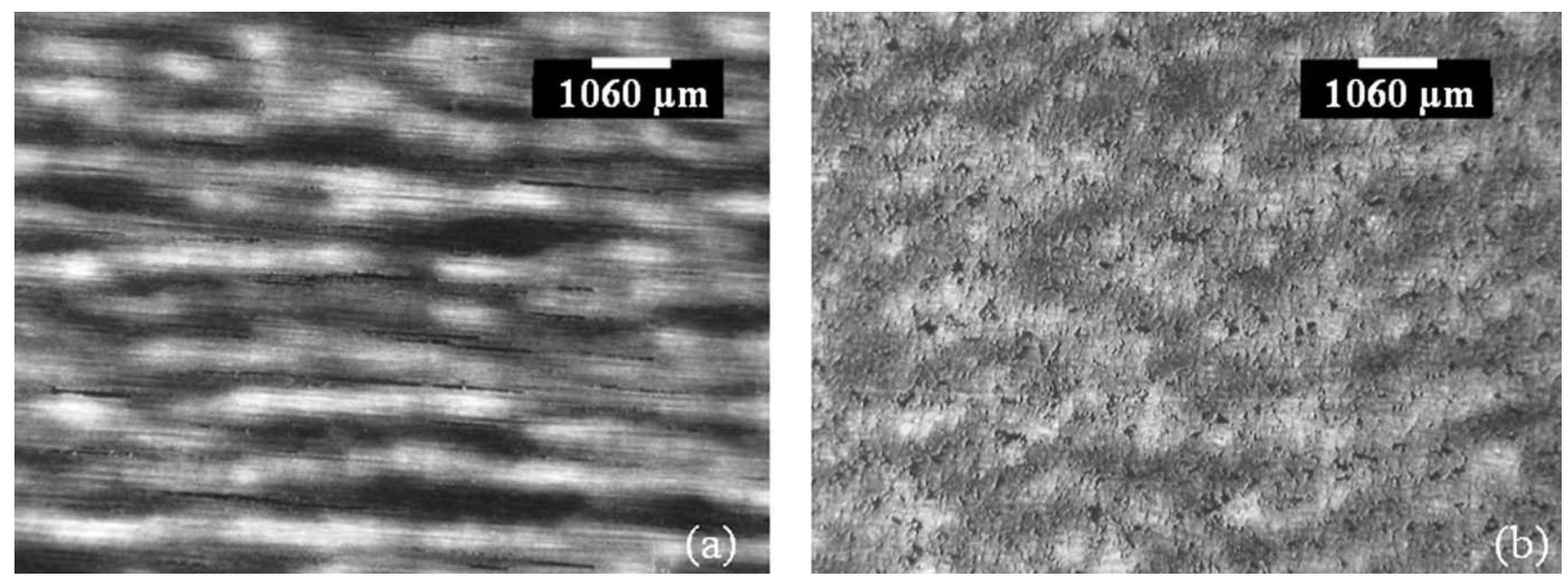

FIG. 11. Effect of the steel sheet surface roughness: steel sheet 1 (a: Sample 1A) and steels sheet 2 (b: Sample 10A).

presenting classical rolling scratches on its surface. In Experiments 10 and 11, the steel sheet 2, presenting a different surface roughness with an alternation of plateaus and valleys (Fig. 5), is used. Figure 11 compares the contact created for the two steel sheets in the nip, for the same process conditions. For steel sheet 2, the photo is less contrasted and clearer, revealing a closer contact than for steel sheet 1 .

Although bubbles can be observed on B-type samples for steel sheet 1 (see for example, Sample 1B), no bubbles are visible at the same observation magnification on B-type samples obtained with steel sheet 2 (Sample 10B). Still, an observation with a higher magnification reveals the presence of some very small bubbles.

Influence of the Polymer Film Thickness. The polymer film thickness coated on the substrate in the next Experiment 11 is twice thinner than in the previous experiments. The resulting contact is less close, as can be deduced from the numerous dark areas observed on Sample 11A. After the postheating stage, it seems that the bubbles are more numerous and bigger when the film is thinner (Sample 11B).

\section{Experiments Discussion and Confirmation of the Origin of the Bubble Defect}

These experimental results lead to several interesting conclusions. First, bubbles appear only on samples that have experienced a postheating stage (B-type samples), which means that the postheating stage is responsible for, at least, the bubbles development.

Figure 3 reveals clearly that bubbles appear at the interface between the steel sheet and the polymer film and not in the polymer thickness. Besides, the bubble shape is circular (Fig. 3), which means that no stress deforms the bubble during its development. This implies that the bubble development does not occur in the nip.
The experimental investigation shows that there is a direct link between the contact quality at the nip exit and the bubble formation: samples revealing a "bad contact" at the nip exit (see for example, Samples 2A, Fig. 7), with numerous dark areas corresponding to loose contact between polymer and substrate, exhibit high bubble size and density after postheating stage. On the contrary, when the contact is closer (see for example, Sample 10A, Fig. 11), with more clear areas, bubbles do not appear after postheating stage (or very small ones).

Finally, these experiments point out the importance of the substrate roughness: even if Samples 1B and 10B are obtained in the same conditions but with two different steel sheets, the first one reveals bubbles and not the second one. The difference between the two steel sheets is only topological: actually, surface analysis shows that there is no chemical difference between the two surfaces, even at $200^{\circ} \mathrm{C}$.

These conclusions confirm the bubble defect origin proposed in Speculation About Bubble Defect Origin section. During coating of the substrate in the nip, air is entrapped at the interface in the substrate roughness and two situations may occur:

The polymer reaches the bottom of all the valleys, and the air at the interface is pushed out. This situation implies, in particular, that there is a way of venting for the air at the interface. It is obvious for the steel sheet 1 , for which the air venting is possible through the rolling scratches. It is less obvious on the steel sheet 2 , but a meticulous observation reveals the existence of "connections" between the valleys. This point was already discussed in our previous article [6].

The polymer flow is stopped before polymer has reached the bottom of some valleys. The remaining entrapped air is blown up into bubbles during the postheating step, and those bubbles can then coalesce. We can suppose that the more air is entrapped, the bigger the bubbles are. 


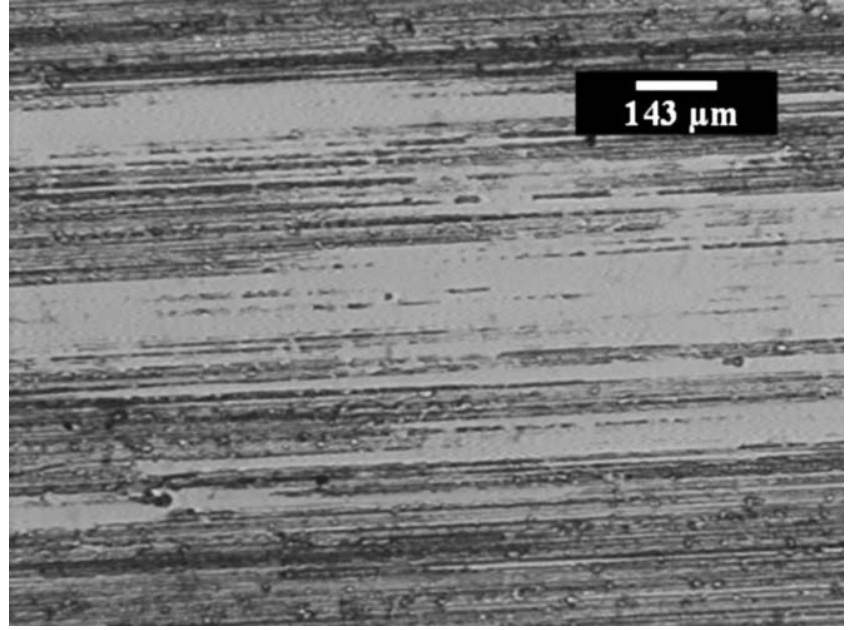

FIG. 12. Observation of the film surface, after extraction from the steel sheet.

This model is consistent with the influence of the process parameters on the bubble defect, described in the previous subsection:

The hotter the substrate, the slower the polymer cools at the interface with the substrate, and the easier it is to fill the substrate roughness: the risk of bubble defect should thus decrease. This is exactly what is observed when comparing Samples 1B and 3B.

The higher the nip load is, the closer the contact between the polymer film and the substrate, and the risk of bubble should thus decrease. Actually, all the Samples 4B-6B show bubbles, and it seems that increasing nip load is not as efficient as increasing the polymer interface temperature.

Increasing the line speed reduces the cooling efficiency of the chill roll: the polymer temperature is higher, and it can flow more easily in the substrate roughness. A similar effect occurs when we stop the chill roll cooling.

The experimental investigations show that there are less bubble defects with the steel sheet 2, which means that the polymer penetrates more easily in the roughness of this substrate. This can be explained because anfractuosities of steel sheet 2 are wider and larger than those of steel sheet 1 . Besides, the bigger bubbles observed for steel sheet 1 can be explained because it is easier for bubbles to coalesce in the scratches of steel sheet 1 than in the pores of steel sheet 2 .

A last observation confirms the bubble defect mechanism proposed above: for A-type samples, the coated film is taken off from the substrate and the side that was in contact with the substrate is observed with a microscope (it is easy to take off the polymer films because for A-type samples, the adhesion is not as strong as for B-type samples):

In the areas where the contact is close, the substrate roughness is totally transferred to the polymer film (for steel sheet 1, for example, we see the rolling scratches transferred to the film);

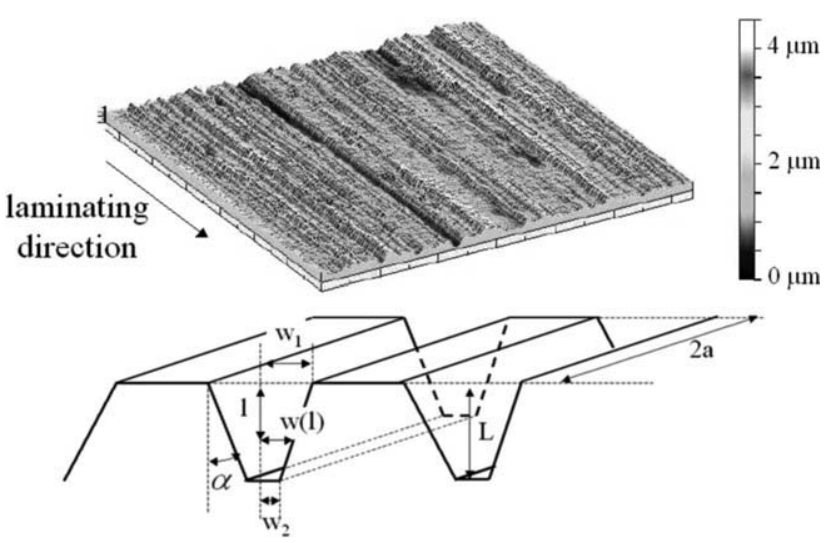

FIG. 13. Film surface (side in contact with the steel sheet 2) for two different film thickness: 309 m (a: Sample 10A) and 159 m (b: Sample 11A).

In the areas where the contact is loose, the polymer film surface is smooth and no roughness transfer is observed. We can assume that, precisely in these areas, air is entrapped between the film and the substrate.

Figure 12 shows such an observation for Sample 2A (preheated temperature substrate $140^{\circ} \mathrm{C}$ ), where many loose areas are present, which explains the numerous bubbles observed on Sample 2B.

Figure 13 provides the same observation for samples obtained with steel sheet 2 . It shows in particular, that the contact is better for high thickness (30 $\mu \mathrm{m}$ : Sample 10A), than for thinner film (15 $\mu \mathrm{m}$ : Sample 11A), explaining the higher number of bubbles for this last sample.

\section{DEFECT APPARITION CRITERION}

It is now possible to propose a simple criterion, able to predict the defect appearance. As observed in the previous section, the bubble defect appears when the polymer melt is unable to chase the air entrapped in the substrate roughness. It means that there will be bubbles whenever the filling time $\left(t_{\mathrm{r}}\right)$ is higher than the residence time in the nip $\left(t_{\mathrm{n}}\right)$.

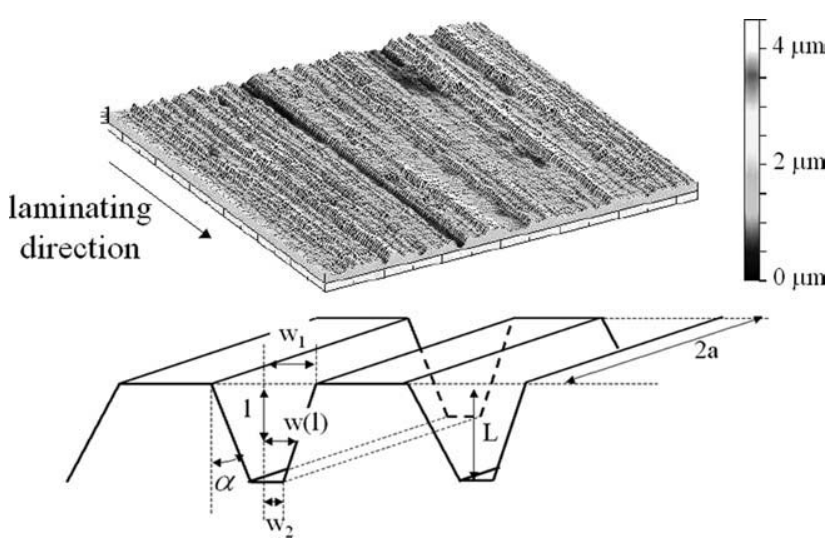

FIG. 14. 3D measured surface topography of steel sheet 1 and its model. 


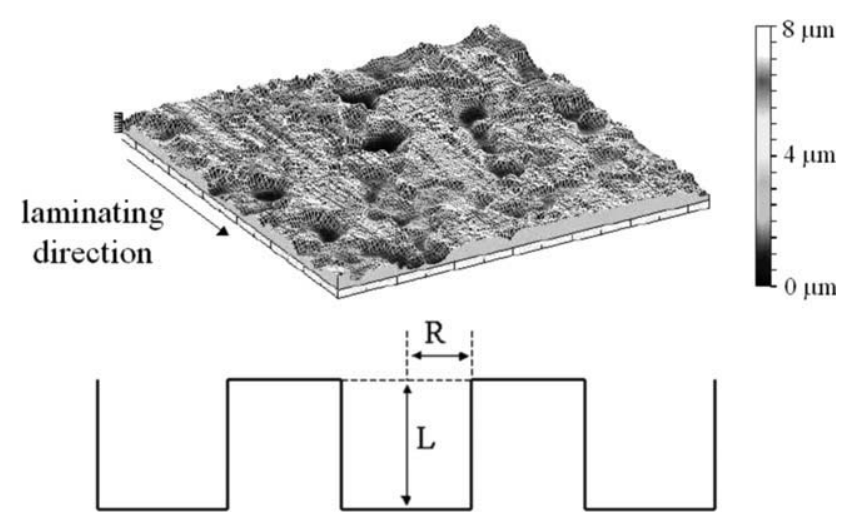

FIG. 15. 3D measured surface topography of steel sheet 2 and its model.

Following Trouillhet et al. [10], we propose the following defect criterion:

$$
\begin{aligned}
& \text { if } t_{\mathrm{r}} \leq t_{\mathrm{n}}: \text { no bubble appears; } \\
& \text { if } t_{\mathrm{r}}>t_{\mathrm{n}}: \text { bubbles may appear. }
\end{aligned}
$$

\section{The Residence Time Calculation}

The residence time depends on the nip dimension ( $a$, the half width of the nip contact) and the line speed $v$, and writes as follows:

$$
t_{\mathrm{n}}=\frac{2 a}{v}
$$

As shown in our previous article [6], the half width of the nip contact can be accurately calculated thanks to the Hertz theory, as a function of the geometrical and elastic characteristics of the rolls (the equivalent reduced radius $R_{\text {eq }}$ and the reduced elastic modulus $E^{*}$ ) and the nip force $F$ :

$$
a=\frac{2}{\sqrt{\pi}} \sqrt{\frac{R_{\mathrm{eq}} \cdot F}{E^{*} \cdot W}}
$$

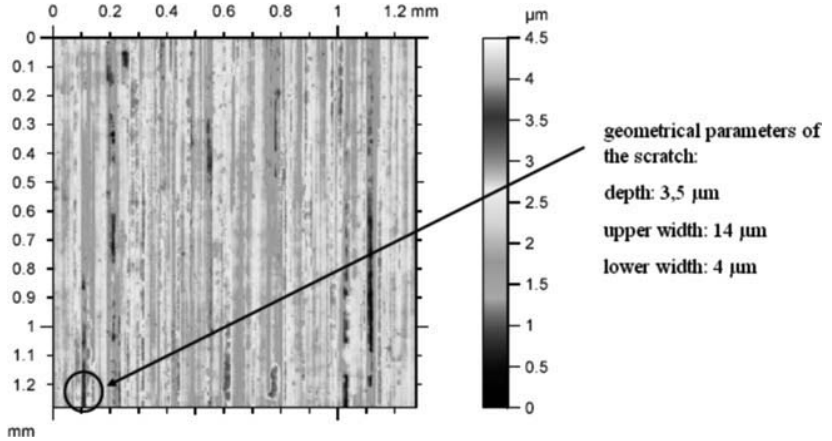

FIG. 16. Geometrical parameters of a scratch difficult to fill on steel sheet 1.

\section{The Filling Time Calculation}

In our study, the polymer used is PET and its rheological behavior is Newtonian. We can suppose that viscosity is the only material property influencing filling time, and we can use the filling time proposed in Ref. 6. If other polymers are used, other parameters such as elasticity or bulk modulus must be taken into account to calculate the filling time.

The filling time expression, proposed in Ref. 6, writes as follows:

$$
t_{\mathrm{r}}=-\frac{\ln \left(1-\beta \cdot t_{\mathrm{r} 0}\right)}{\beta}
$$

The way to calculate the value of the two factors $t_{\mathrm{r} 0}$ and $\beta$ are developed below.

The first factor in Eq. 5, $t_{\mathrm{r} 0}$, is the filling time in isothermal conditions, called "constant viscosity filling time". It depends on the polymer viscosity $\eta_{0}$, the mean pressure $p_{\mathrm{m}}$ developed in the nip (given by the Hertz theory, see Ref. 6) and on several geometrical parameters of the substrate roughness. Its general expression is reminded here:

$t_{\mathrm{r} 0} \propto \frac{\eta_{0}}{p_{\mathrm{m}}} \cdot f$ (geometrical parameters of the roughness)

For steel sheet 1 , the rolling scratches can be assimilated with dihedrons of depth $L$ and slope $\alpha$ (flank angle),

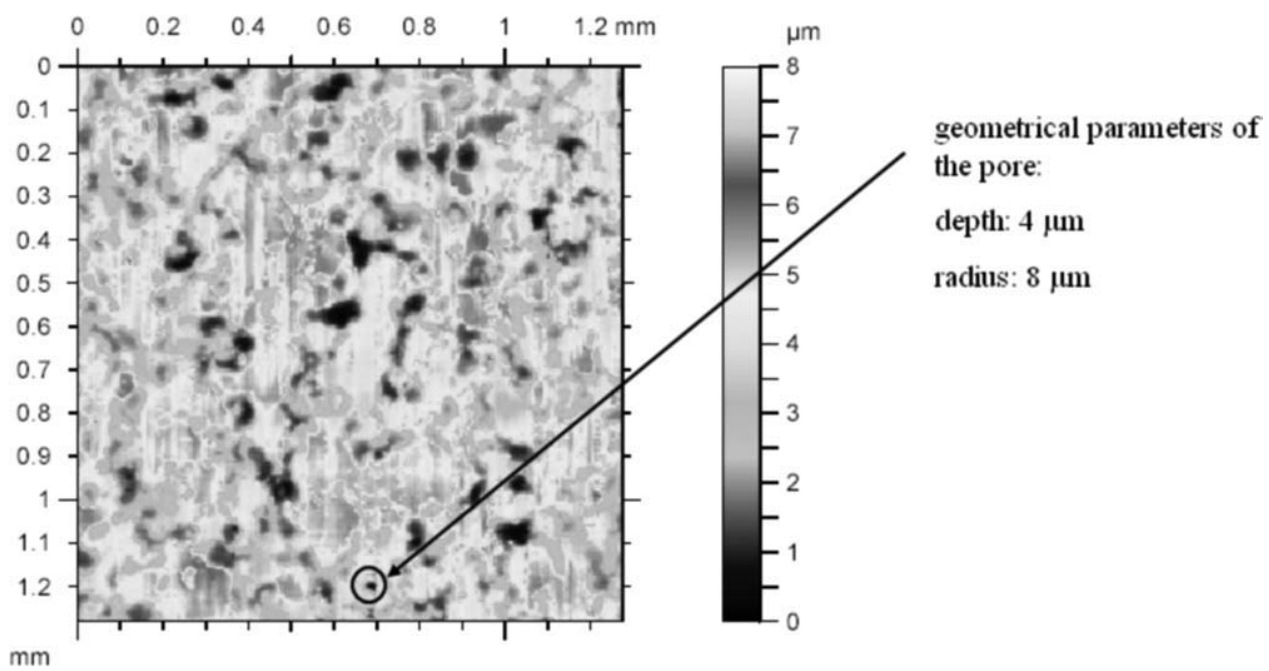

FIG. 17. Geometrical parameters of a pore difficult to fill on steel sheet 2 . 


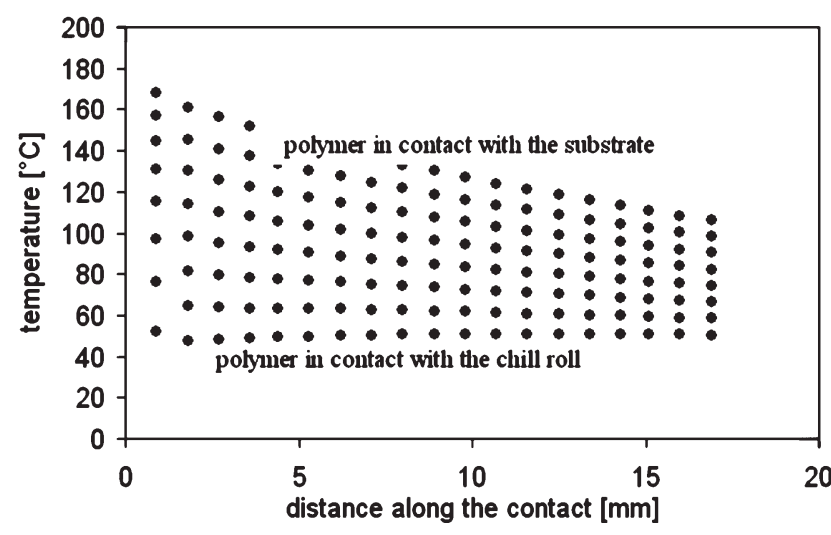

FIG. 18. Temperature evolution in the polymer film thickness near the substrate (10 first microns).

$w_{1}$ and $w_{2}$ are lengths defining the entry and the bottom of the dihedron, respectively, as shown Fig. 14. The resulting filling time (in isothermal conditions), $t_{\mathrm{r} 0}$ writes (see Ref. 6):

$$
\begin{array}{r}
t_{\mathrm{r} 0}=\frac{2 \eta_{0}}{p_{\mathrm{m}}}\left(\frac{\tan ^{2} \alpha+\tan ^{4} \alpha}{\tan \alpha-\alpha+\alpha \tan ^{2} \alpha}\right)\left[\frac{w_{1}}{w_{1} \tan \alpha-L \tan ^{2} \alpha}\right. \\
\left.-\frac{1}{\tan \alpha}-\frac{L}{w_{1}}\right]
\end{array}
$$

For steel sheet 2, the roughness may be considered as a succession of cylindrical pores, of various radii $R$ and depths $L$, as shown Fig. 15. The resulting filling time (in isothermal conditions), $t_{\mathrm{r} 0}$ writes (see Ref. 6):

$$
t_{\mathrm{r} 0}=\frac{4 \eta_{0} L^{2}}{p_{\mathrm{m}} R^{2}}
$$

The values of the geometrical parameters are deduced from the 3D measured surface topographies. For both steel sheets, we first measure their surface roughness and then determine the dimensions of the most critical anfractuosities, that is to say those which are the most difficult to fill. Examples of those critical anfractuosities are given in Fig. 16 for the steel sheet 1 (a deep and narrow scratch, with a high flank angle) and Fig. 17 for the steel sheet 2 (a deep pore with a small enter radius). The filling times corresponding to these anfractuosities can be considered as maximum values.

The second factor in $E q .5, \beta$, expresses the viscosity variation as a function of time in the laminator. We assume that this variation is exponential:

$$
\eta=\eta_{0} \cdot \exp (\beta t)
$$

The thermal model developed at Arcelor Research and presented in our previous article [6] allows to predict the temperature variation in the polymer thickness along the nip. Typical results obtained with this model are presented in Fig. 18. As shown in Fig. 19, we consider only the temperature variation of the polymer at the interface, near the substrate, on a thickness of $10 \mu \mathrm{m}$ (mean depth of the anfractuosities). Taking the mean temperature on this thickness, we can deduce, thanks to the Arrhenius law, the variation of the mean viscosity of the polymer as a function of the residence time in the nip (Fig. 20). The obtained curve can be fitted by an exponential law, and the parameters $\eta_{0}$ and $\beta$ are deduced from this curve fitting. For example, in the conditions of Fig. 20, we obtain: $\eta_{0}=7500 \mathrm{~Pa} \mathrm{~s}$ and $\beta=26 \mathrm{~s}^{-1}$.

\section{Predictive Character of the Criterion}

We calculate now the residence and filling times for all the experimental conditions presented in Experimental Investigation section. By comparing the residence time in the nip and the filling time of these anfractuosities, we deduce the creation or the absence of bubbles. This theoretical result is compared with the experimental observations. As pointed out in Table 4, in all cases, except Experiment 8 , the criterion is able to predict the defect appearance. Most of the calculated filling times are infinite, meaning that the cooling is so strong that the polymer cannot reach the bottom of the anfractuosities.

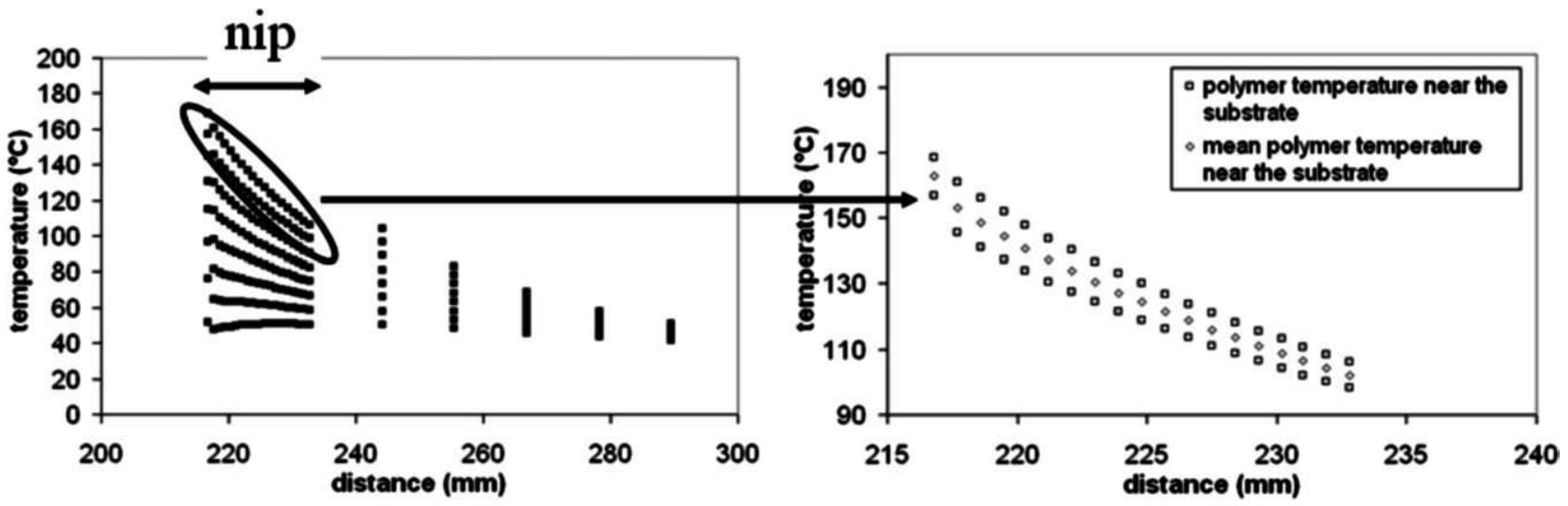

FIG. 19. Temperature evolution in the polymer thickness along the nip (results obtained with the thermal model developed at Arcelor-Mittal Research Centre). 


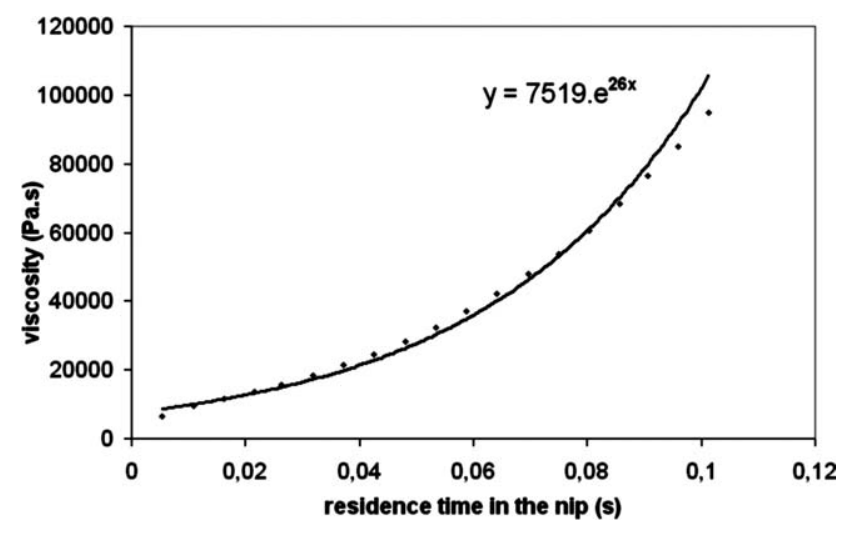

FIG. 20. Mean viscosity evolution vs. residence time in the nip.

The slight disagreement for Experiment 8 underlines the numerous limitations and approximations of the model, especially concerning the following two points:

The anfractuosities dimensions are determined quite roughly and on an area which is not representative of all the substrate surface.

The temperature dependence of the viscosity is supposed to follow an Arrhenius law. This relationship describes quite properly the viscosity evolution above the melting temperature but underestimates the viscosity for temperatures close to the crystallization range or to the glass transition.

\section{CONCLUSIONS}

On the basis of an analysis of the thermomechanical phenomena occurring in the nip of the extrusion coating

TABLE 4. Calculation of the two characteristic times for the different experiments of Table 2 .

\begin{tabular}{lrrrrrr}
\hline $\begin{array}{l}\text { Experiment } \\
\text { no. }\end{array}$ & $\begin{array}{l}\text { Residence } \\
\text { time, } t_{\mathrm{n}}(\mathrm{s})\end{array}$ & $\eta_{0}(\mathrm{~Pa} \mathrm{~s})$ & $\beta\left(\mathrm{s}^{-1}\right)$ & $\begin{array}{c}\text { Filling } \\
\text { time, } t_{\mathrm{n}}(\mathrm{s})\end{array}$ & $\begin{array}{c}t_{\mathrm{r}}>t_{\mathrm{n}} \\
\text { observation }\end{array}$ \\
\hline 1 & 0.11 & 7500 & 26 & $\propto$ & Yes & Yes \\
2 & 0.11 & 40,000 & 24 & $\propto$ & Yes & Yes \\
3 & 0.11 & $4.10^{6}$ & 13 & $\propto$ & Yes & Yes \\
4 & 0.09 & 6000 & 28 & $\propto$ & Yes & Yes \\
5 & 0.12 & 6300 & 25 & $\propto$ & Yes & Yes \\
6 & 0.14 & 7000 & 29 & $\propto$ & Yes & Yes \\
7 & 0.07 & 4500 & 29 & $\propto$ & Yes & Yes \\
8 & $\mathbf{0 . 0 5 5}$ & $\mathbf{3 7 0 0}$ & $\mathbf{3 2}$ & $\mathbf{0 . 1 2}$ & Yes & No \\
10 & 0.11 & 8000 & 26 & 0.0095 & NO & No \\
11 & 0.11 & 19,000 & 65 & $\propto$ & Yes & Yes \\
\hline
\end{tabular}

process, we explain the origin of the bubble defect, seriously affecting the aesthetic aspect, the barrier properties, and the mechanical strength of the coated substrate. During the coating of the polymer film, air is entrapped at the interface in the anfractuosities of the substrate surface. Depending on the residence time and on the cooling conditions in the nip, this air can be either totally or partially chased by the nip load. If not totally chased, the remaining entrapped air is blown up during the postheating step of the process into bubbles. An experimental investigation of the influence of some process parameters on the bubble creation confirms this defect origin. This investigation leads to the conclusion that the surface roughness is a determinant factor for the bubble defect. The best way to avoid bubble defect is to choose a surface roughness with easy venting way for the air.

A simple criterion able to predict the appearance of the defect is proposed. It requires a local micromechanical model at the interface between polymer and metal. There is a fair agreement between the model and the experimental results, which allows to use it as a predictive tool or as an optimization tool for the process.

\section{REFERENCES}

1. J.P. Goslin and H.F. Sweeney, Tappi J., 43, 434 (1960).

2. J.E. Guillote and T.F. McLaughlin, Tappi J., 45, 200 (1962).

3. F.M. Hammond and M.H. Hansen, Tappi J., 74, 232 (1991).

4. J. Kuusipalo and A. Savolainen. J. Adhes. Sci. Technol., 11, 1119 (1997).

5. A. Stralin and T. Hjertberg, J. Adhes. Sci. Technol., 7, 1211 (1993).

6. C. Sollogoub, E. Felder, Y. Demay, J.F. Agassant, P. Deparis, and N. Mikler, Polym. Eng. Sci., 48, 1634 (2008).

7. R.T. Van Ness, Tappi J., 54, 731 (1971).

8. W.M. Karszes, “1990 Polymers, Laminations \& Coatings Conference," in the TAPPI Proceedings, TAPPI Press, Atlanta, GA, 621 (1990).

9. W.M. Karszes, Tappi J., 58, 203 (1992).

10. Y. Trouilhet and B.A. Morris, "1999 Polymers, Laminations \& Coatings Conference," in the TAPPI Proceedings, TAPPI Press, Atlanta, GA, 457 (1999).

11. B.W. Foster and R. Edwards, "1993 Polymers, Laminations \& Coatings Conference," in the TAPPI Proceedings, TAPPI Press, Atlanta, GA, 415 (1993). 